Integritas 2.1 (Fall 2013), pp. 1-13.

doi: 10.6017/integritas.v2i1p1

\title{
Get Rich U or Get Transformed U: Reflections on Catholic Liberal Arts Education in the 2Ist Century
}

\author{
Thomas G. Plante
}

Catholic liberal arts educators can proclaim boldly that we are in the business of formation and transformation of students at multiple levels and in multiple ways. We want our students to be competent, ethical, and compassionate global citizens who are thoughtful, savvy, deep thinkers who love learning and who love helping others. Research and best practices support the claim that the virtues cultivated by the liberal arts contribute to the flourishing of individuals and society as a whole. Catholic colleges and universities have a long history of promoting the liberal arts, and data

from various sources suggest that we are doing it well. Unfortunately, students, parents, and society at large often fail to understand and appreciate their value in an era of both widespread materialism and job insecurity. This paper will explore how evidence from contemporary research and best practices suggests that there is still perennial value in the liberal arts.

\section{Is the Goal of Higher Education to Get Rich?}

In a recent article entitled "Get Rich U" published in The New Yorker magazine, Ken Auletta discussed the overly close and cozy relationship between Stanford University

Thomas G. Plante, Ph.D., ABPP, is the Augustin Cardinal Bea, S.J., University Professor teaching in the Psychology Department and directs the Spirituality and Health Institute at Santa Clara University. He also is an Adjunct Clinical Professor of Psychiatry and Behavioral Sciences at Stanford University School of Medicine where he teaches professional ethics. He has served as Psychology Department Chair as well as Acting Dean of the School of Education, Counseling Psychology, and Pastoral Ministries at Santa Clara University. He recently served as Vice Chair of the National Review Board for the Protection of Children and Youth for the U.S. Conference of Catholic Bishops and is past-president of the Society for the Psychology of Religion and Spirituality (Division 36) of the American Psychological Association. 
and Silicon Valley companies. ${ }^{\mathrm{I}}$ In the provocative article the author states, "There are no walls between Stanford and Silicon Valley" and then asks, "Should there be?" Stanford, often listed as the top university in the United States among numerous national polls, is the current "it" school with a more competitive and selective acceptance rate for their undergraduate programs than any other college or university in the United States (including traditionally highly competitive and selective universities such as Harvard, Yale, and Princeton). Computer science is now listed as the most popular major at Stanford with many students desiring to seek post-Stanford fortunes in the Silicon Valley business world. ${ }^{2}$ Perhaps they are attempting to model themselves as the next Steve Jobs from Apple, Mark Zuckerberg from Facebook, or Larry Page/Sergey Brin from Google, who all made billions in Silicon Valley through life-changing and technologically innovative computer science-driven start-up companies.

A follow-up article also published in The New Yorker magazine entitled "Laptop U" more recently explored the explosion of online education and the efforts of Stanford, MIT, Cornell, and several other leading universities to produce more highly profitable online learning experiences. ${ }^{3}$ These trends, among many others, highlight efforts by universities and students alike to find ways to maximize earnings as a goal or at least as a by-product of contemporary higher education.

These current and well-publicized developments contribute to the perception that traditional liberal arts education might be a quaint relic of the past, and that higher education that maximizes success in the business and technology world is really where the action is and the future resides. Business is by far the most popular college major in the United States, representing almost a quarter of all undergraduate degrees earned. ${ }^{4}$ And in a recent provocative article, 9 of the ro top "worthless majors" were in liberal arts, including philosophy, communications, psychology, music, and so forth. ${ }^{5}$ The ioth "worthless major" was education! PayPal founder Peter Thiel now offers 20 \$100,000 grants per year through his Thiel Foundation to students under the age of 20 to drop out of college in order to start their own companies. Yes, just like Steve Jobs, Mark Zuckerberg, Bill Gates (from Microsoft), Larry Ellison (from Oracle), and many other famous, wealthy, and successful technology titans, students are dropping out of college in order to pursue their get-rich dreams in business and technology, and are being encouraged to do so by the Thiel Foundation among others.

The continuing rising costs of higher education, the inability of many college graduates to find satisfying, relevant, and gainful employment within their areas of study after graduation, the increase in and acceptance of long-term unpaid internships for a year or

\footnotetext{
Ken Auletta, "Get Rich U," The New Yorker, April 30, 2012, 38-47.

2 Kylie Jue, "Computer Science Becomes Stanford's Most Popular Major," The Stanford Daily, July 19, 2012.

3 Nathan Heller, "Laptop U: Is College Moving Online?" The New Yorker, May 20, 2013.

4 "Most Popular Majors - Fast Facts," National Center for Educational Statistics.

5 Brenden Gallagher, "The 10 Most Worthless College Majors," Complex, April 11, 2013.
} 
more after college graduation, and higher expectations for luxury and glamorous living all contribute to the view that liberal arts education is either dead or dying. ${ }^{6}$ Why should students consider majoring in liberal arts academic disciplines in 2014 and beyond? Is it foolish for today's college students to major in the humanities, performing arts, social sciences, and even the natural sciences when the business, computer science, and engineering fields are so much more marketable, profitable, and popular? Could it be that a liberal arts education is only for those who are independently wealthy and thus won't need to worry about earning a living after graduation? This current state of affairs poses serious questions about the future of not only liberal arts higher education in general but perhaps liberal arts education within the Catholic tradition in particular.

Our American culture has evolved in such a way to highly value and perhaps even worship money, celebrity, and quick routes to fame and fortune. Perhaps mass media as well as social media have made these matters much worse. While higher education is valued in that more and more Americans are attending and graduating from both two- and four-year colleges, many appear to see higher education as a ticket to a higher paying job. Students, in more recent years, are much more interested in making money than ever before and certainly more than other goals in education, such as developing a meaningful philosophy of life, growing as a person, and engaging with diverse peoples and views, as reported by the yearly UCLA-hosted Cooperative Institutional Research Program (CIRP) Freshman Survey published by the Higher Education Research Institute. ${ }^{7}$ The view seems to be that higher education is a means to an end, and that end is a high-paying job.

So, is liberal arts higher education dying in America? Does this traditional form of education have a terminal illness needing hospice care? Should top universities, like Stanford, be smart and cutting edge by continuing to put more and more resources into computer science and technology education closely collaborating with business and industry? And what makes Catholic liberal arts education of any value in today's highly competitive marketplace? If liberal arts education is dying, might Catholic liberal arts education be already dead and buried?

\section{In a Word, No!}

\section{The Hidden Benefits of Liberal Arts Education}

While liberal arts education (and within the Catholic tradition) might, on the surface, appear to be old fashioned, out-of-date, extravagant, and now even countercultural, it is critical to support and nurture it, perhaps more than ever, for several important reasons. First, the ability to engage in thoughtful, meaningful dialogue is a critical skill that liberal arts education reinforces, develops, and nurtures quite well. In a climate of quick sound bites and polarized arguments where those who scream louder win, the ability to engage in deep, thoughtful, nuanced thinking, reflection, and discussion is an important and

6 Gallagher, "The 10 Most Worthless College Majors" and John Robst, "Education and Job Match: The Relatedness of College Major and Work," Economics of Education Review 26, no.4 (2007), 397-407.

"The CIRP Freshman Survey," Higher Education Research Institute. 
valuable tool to have and to use. Second, current technical and practical skills can become obsolete very quickly in a rapidly changing and ever-evolving marketplace and world. Yet, critical thinking and problem-solving skills based on thoughtful and careful critical analysis as well as the ability to appreciate, work with, and even celebrate diversity never goes out of style. In the words of Santa Clara University scholars Diane Jonte-Pace and Phyllis Brown "...we need to cultivate habits of the mind and heart that allow for positive contributions in a rapidly changing, complex, and interdependent world." 8

In fact, a recent comprehensive national survey of employers found that most companies value the kinds of thinking and problem-solving skills secured and nurtured through liberal arts education much more than the technical skills obtained in more practical vocational-based training environments. ${ }^{9}$ Specifically, $93 \%$ of companies surveyed agreed that a job applicant's "demonstrated capacity to think critically, communicate clearly, and solve complex problems is more important than their undergraduate major." Over $90 \%$ of companies claimed that new job hires should demonstrate "ethical judgment and integrity, intercultural skills, and the capacity for continued new learning." Over $75 \%$ of companies wanted colleges to "put even more emphasis on helping students develop critical thinking, complex problem solving, and written and oral communication skills." Finally, 96\% reported that their new job hires were "at ease working with colleagues, customers, and clients from diverse cultural backgrounds." Thus, contemporary employers overwhelmingly preferred the types of skills that are developed, nurtured, and supported by liberal arts higher education.

\section{A recent comprehensive national survey of employers found that most companies value the kinds of thinking and problem-solving skills secured and nurtured through liberal arts education much more than the technical skills obtained in more practical vocational-based training environments.}

Liberal arts education highlights the very skills and approaches much needed today. A focus on critical thinking, diversity, good reading, writing, and oral communication skills, thoughtful and reasoned inquiry, and a love of and engagement in learning are all qualities that should be nurtured in our young citizens. Liberal arts education attempts to fully engage students in an academic discipline that hopefully enlivens and enriches

8 D. Jonte-Pace and P. Brown, "Ignatian Values in the Core Curriculum," Conversations on Jesuit Higher Education 38 (2010), 37-38. 
them, awakens their natural curiosity and love of learning, and develops their gifts and interests. The study of music, art, literature, social sciences, humanities, and natural sciences in depth and with others hopefully results in a fuller and more long-lasting education, and stimulates a passion for life-long learning as well. In the words of the American Academy of Arts and Sciences in a recent report on the humanities and social science education, "A fully balanced curriculum-including the humanities, social sciences, and natural sciences_-provides opportunities for integrative thinking and imagination, for creativity and discovery, and for good citizenship...they are critical to our pursuit of life, liberty, and happiness, as described by our nation's founders."

\section{But Why Bother with a Catholic Liberal Arts Education?}

Our Catholic values and tradition offers a value-added approach to higher education in general and in liberal arts education in particular. It does more than merely add a few required religious studies classes to a core curriculum similar to those offered in other non-Catholic and some secular colleges and universities. It does more than offer Catholic Masses on campus and a campus ministry office. It infuses all that we do on campus both in and outside of the classroom. Fundamental issues such as social justice, ethics, spirituality, and hospitality are reinforced and nurtured throughout campus life. Perhaps, at its very best, Catholic liberal arts education seeks ways to discover our Godgiven gifts and to use reflection and discernment processes to apply these gifts to help solve the world's greatest needs and problems. ${ }^{\text {II }}$

Our gifts are not only for our own glory, aggrandizement, or unlimited personal financial gain but also to serve others (most especially those with great need) consistent with God's will and plan for us as we come to understand and discern it. It hopes to "foster engaged citizenship and refined self-knowledge in relation to others." ${ }^{\text {I2 }}$ We believe that this connection with education and building a better world can lead to a more satisfying and transformative life rather than using our education solely for our personal gratification and financial gain. As discussed in the Spiritual Exercises of St. Ignatius, this ultimately leads to a sense of consolation rather than desolation. ${ }^{13}$

Perhaps several examples may prove useful to illustrate the transformational value of Catholic liberal arts education.

\section{Example 1: Oscar the Doctor}

Oscar is a pediatric kidney transplant surgeon at Stanford University Hospital and Medical Center. He was a surgeon in the Vietnam War and worked very closely with

10 American Academy of Arts and Sciences, The Heart of the Matter: The Humanities and Social Sciences for a Vibrant, Competitive, and Secure Nation (2013).

11 D.E. Dreher and T.G. Plante, "The Calling Protocol: Promoting Greater Health, Joy, and Purpose in Life," in Spirit, Science and Health: How the Spiritual Mind Fuels the Body, eds. T.G. Plante \& C.E. Thoresen (Westport: Greenwood Publishing Group, 2007), 129-142; Jonte-Pace and Brown, 37-38.

12 Jonte-Pace and Brown, 38.

13 George E. Ganss, S.J., Ignatius of Loyola: The Spiritual Exercises and Selected Works (New York: Paulist Press, 1991). 
former Vice President Al Gore on the Agent Orange problem among veterans. Oscar does not consider himself to be a religious man and is not affiliated with any organized religious tradition. However, as a former undergraduate student and graduate of Georgetown University majoring in English and philosophy, in reflection he attributes much of his success and who he has become as a person to his Jesuit and Catholic higher education experiences as a college student. He states that the Jesuits and lay professors at Georgetown taught him how to write, think clearly, communicate effectively, and to really care about and appreciate others, especially those in greatest need. Dinner party conversations with this close friend and neighbor always turn to our mutual love of mentoring students and to the value of and challenges within Jesuit higher education today. Oscar is an excellent example of the transformative and long-lasting influence of Catholic higher education over the life span, even for someone who does not identify as a Catholic or practice any religion at all.

Additionally, Catholic tradition and values also support a more integrated, holistic, and inclusive view of the person. We seek to educate body, mind, and soul to serve God and others. Furthermore, we don't demand that our educational approach is only for Catholics, Christians, or believers in general. As Jesus invites his listeners as reported in the Gospels, we maintain a "come and see" attitude. In a nutshell, we invite students to "come to our educational approach and tradition that embraces ethics, compassion for others, holistic education, and the highest educational and intellectual standards and ideals that help build a better and more just and humane world. Enjoy our hospitality, graciousness, and even love." Perhaps this is Catholic higher education at its very best: using ourselves as earthen vessels of God's great love and grace to help make a better world for all of us through transformational experiences and learning with others.

Catholic liberal arts education is not just about finding a high-paying job after graduation (although that may be a welcomed outcome). It is more about being "engaged, inspired, and ultimately transformed." ${ }^{44}$ Helping students discover their interests and gifts and allowing God's grace to find a place to use these interests and gifts to serve others and make the world a better place is what Catholic higher education is all about.

\section{Example 2: Randy the Ethical Baseball Player}

After graduation from Santa Clara University, Randy spent I3 years as a professional baseball player associated with several quality teams including the San Francisco Giants, the New York Yankees, the St. Louis Cardinals, and the Seattle Mariners. During one critical late-season game during the final week of a long season, Randy was playing for the Giants in a game with the San Diego Padres that was nationally televised as the featured Fox Game of the Week. The winner of the three-game series would win the division and play in the playoffs, while the losing team would see their season come

14 G. M. Manuel, "Spiritual Practices in Psychotherapy: Thirteen Tools for Enhancing Psychological Health" (Workshop presented with T.G. Plante at the 121st annual meeting of the American Psychological Association, Honolulu, $\mathrm{HI}, 2013$ ). 
to an abrupt end. Late in a very close and tense game, Randy slid into third base and the ball popped out of the third baseman's glove, rendering Randy safe. The television announcers wondered if Randy may have done something to help get the ball out of the glove of the Padres' third baseman, as some players such as A-Rod with the New York Yankees had famously done during a critical playoff game against the Boston Red Sox just a few years earlier. One announcer dismissed the possibility that Randy would try to get the third baseman to drop the ball, confidently stating that "Randy wouldn't do that ...he's a Santa Clara guy." The fellow announcers agreed and they moved on to another topic. The message was clear: as a graduate of a quality Jesuit, Catholic college education at Santa Clara, Randy was and is assumed to be a person of integrity and ethics. $\mathrm{He}$ wouldn't cheat.

In a nutshell, we invite students to "come to our
educational approach and tradition that embraces ethics,
compassion for others, holistic education, and the highest
educational and intellectual standards and ideals that help
build a better and more just and humane world. Enjoy our
hospitality, graciousness, and even love."

This example is further supported and reinforced by several other well-known Santa Clara athletes and my former psychology students, including basketball star Steve Nash and baseball player Daniel Nava, who are well known for their community engagement, ethical behavior on and off the playing field, and refreshing graciousness.

\section{Example 3: Jennifer the Professor}

Jennifer was a psychology major coming to the end of her junior year at Santa Clara. She plopped herself in my office one day and, as so many students do as they come toward the end of their college career, expressed great anxiety and some fear about what to do after college. Although she enjoyed her psychology major and core curriculum experience at Santa Clara, she was uncertain about what educational or career path she wanted to follow. After going through the calling protocol that uses Ignatian reflection and strategies of discovery, detachment, discernment, and direction (the four Ds), she joined my health psychology research lab to see if health psychology research might interest her and better help her discern her vocational calling. ${ }^{15} \mathrm{After}$ working on several projects, presenting her work as the only undergraduate student to do so at the annual

15 D.E. Dreher and T.G. Plante, "The Calling Protocol: Promoting Greater Health, Joy, and Purpose in Life," in Spirit, Science and Health: How the Spiritual Mind Fuels the Body, eds. T.G. Plante \& C.E. Thoresen (Westport: Greenwood Publishing Group, 2007), 129-142. 
Society of Behavioral Medicine convention in Washington, DC, and publishing several academic papers with other students and myself, she caught fire, found her path and calling, and is now a tenured professor of psychology at a Catholic university. She is an engaged and active Catholic integrating her faith and academic work within a highquality Catholic university.

\section{Example 4: Sara and the Homeless}

As part of her Abnormal Psychology class, Sara was asked to participate in a universitysponsored community-based learning experience where she spent two hours per week volunteering at a homeless shelter for mentally ill clients. Sara freely admitted that she was scared and uncomfortable about working with homeless patients, and considered dropping the class to avoid the experience. After addressing her concerns during office hours, she realized that although she was very uncomfortable, she knew that if she was going to be a psychology major she would learn a great deal at the shelter and in the class. With appropriate confidentiality arrangements, Sara discussed her experiences in class, wrote a compelling reflection paper on them, and discovered that one of the clients that she was closely working with at the shelter had a diagnosis in his chart that was not correct. After discussing her concerns in class and with her fellow students, she worked with the staff of the facility pointing out the diagnostic and treatment error. The staff agreed with Sara's assessment, the medical chart was altered, and a new and more appropriate treatment protocol was started for the patient. Sara decided to stay on at the shelter after the course was completed as an intern, as she became more and more fascinated and interested in severe mental illness. Over time, she discovered a calling to try to best assist this population. These experiences and transformation led her to pursue doctoral studies in clinical psychology. She returned to her hometown and now specializes as a clinical psychologist in post-traumatic stress disorder among military veterans, working at the VA hospital and in private practice.

We are currently examining whether elements of
liberal arts education are associated with enhanced
compassion during their college years, with preliminary
analyses finding strong positive correlations between
these elements and compassion scores.

\section{Empirical Research}

While case examples and testimonials certainly have their place, quality empirical research is better able to more fully demonstrate the value of Catholic liberal arts education. Efforts have been underway in various locations to help empirically demonstrate the transformative nature of Catholic higher education in the liberal arts. For example, 
we have sought to determine if elements of this educational model enhance the development of compassion in students. Many Catholic universities have "faith that does justice" community-based learning immersion programs that take students to domestic and international locations to work in solidarity with the poor and marginalized. We have found that students who participate in these programs not only improve their levels of compassion for others (assessed using a reliable and validated compassion inventory and evaluated before, immediately after, and several months following a campus-sponsored immersion trip compared to a matched comparison group), but they also coped with perceived stress and daily hassles much better too. ${ }^{16}$ All students at Santa Clara now are required to participate in at least one community-based learning immersion (called experiential learning for social justice) class regardless of their academic major as well as take the compassion inventory when they enter the university and when they graduate. We are currently examining whether elements of liberal arts education (e.g., selected major, community-based learning experiences, campus ministry involvement) are associated with enhanced compassion during their college years, with preliminary analyses finding strong positive correlations between these elements and compassion scores. ${ }^{\text {I7 }}$

Additionally, empirical research has found that elements of spiritual and religious practices and engagement are associated with enhanced psychological and physical health and improved well-being that includes less anxiety, depression, alcohol consumption, and many other benefits to college students. ${ }^{18}$ For example, our research has also demonstrated that contemplative and meditative practices among college students result in enhanced well-being by lowering stress and enhancing forgiveness skills. ${ }^{19}$ Thus, elements of Catholic liberal arts education have been associated with improved psychological, behavioral, and physical functioning among college students using state-of-the-art randomized clinical trial research methodology. This is especially

16 J. Y. Hwang et al., "The Development of the Santa Clara Brief Compassion Scale: An Abbreviation of Sprecher and Fehr's Compassionate Love Scale," Pastoral Psychology 56(4) (2008): 421-428; B.A. Mills, R.B. Bersamina, and T.G. Plante, "The Impact of College Student Immersion Service Learning Trips on Coping with Stress and Vocational Identity," The Journal for Civic Commitment, 9 (2007): 1-8; T.G. Plante, K. Lackey, and J.Y. Hwang, "The Impact of Immersion Trips on Development of Compassion Among College Students," Journal of Experiential Education 32 (1) (2009), 28-43.

17 T. G. Plante and E. Callister, "Does Faith that Does Justice Education Improve Compassion?" in The Psychology of Compassion: Understanding the Emotional, Spiritual, and Religious Influences, ed. T.G. Plante (Santa Barbara: Praeger/ABC-CLIO, in preparation).

18 T.G. Plante, and A.S. Sherman, eds., Faith and Health: Psychological Perspectives (New York: Guilford, 2001); T.G. Plante and C.E. Thoresen, eds., Spirit, Science and Health: How the Spiritual Mind Fuels Physical Wellness (Westport: Praeger/Greenwood, 2007); T.G. Plante, Spiritual Practices in Psychotherapy: Thirteen Tools for Enhancing Psychological Health (Washington: American Psychological Association, 2009); T.G. Plante, ed., Religion, Spirituality, and Positive Psychology: Understanding the Psychological Fruits of Faith (Santa Barbara: Praeger/ABC-CLIO, 2012).

19 D. Oman et al., "Meditation Lowers Stress and Supports Forgiveness Among College Students: A Randomized Controlled Trial," Journal of American College Health, 56 (2008), 569-578; S.L. Shapiro et al., "Does Mindfulness Mediate Well-Being Effects? A Controlled Empirical Trial," Journal of Clinical Psychology, 64 (2008), 1-22. 
important since many have reported that college students are vulnerable to affective, substance abuse, and eating disorders as well as other mental health troubles. ${ }^{20}$

It is also important to mention that liberal arts education within the Catholic tradition is not opposed to professional, technical, and business education. Certainly, many quality Catholic universities offer undergraduate and graduate degrees in these fields. However, these programs tend to at least include elements of traditional liberal arts education within their core curriculum so that engineering, business, and technical fields have at least some exposure to and experience with humanities, arts, social science, and other liberal arts courses. Many also offer community-based learning experiences and immersion programs for those focused on technical and business education as well. In fact, even secular and non-liberal arts schools have come to the conclusion that technical and professional education needs to be informed by the liberal arts, according to a recent Carnegie Foundation report. Thus, Catholic colleges and universities offer value-added elements to technical and professional fields that incorporate parts of Catholic liberal arts education. ${ }^{2 \mathrm{I}}$

\section{Conclusion}

After teaching at a Catholic (and Jesuit) university for 20 years, I can honestly say to my students, "Come and see...reflect, discern, and let yourself be transformed in our community that wants to help 'engage, inspire, and transform' you to become a person of 'competence, conscience, and compassion,' and to use your God-given gifts to help create a life that is worth living and sharing with others for the benefit of all." ${ }^{22}$

Catholic liberal arts education can proclaim boldly that we are in the business of formation and transformation of students at multiple levels and in multiple ways. We want our students to be competent, ethical, and compassionate global citizens who are thoughtful, savvy, deep thinkers who love learning and who love helping others. We want them to discover their gifts and to reflect, discern, and explore how to use their very special gifts and talents in the service of others and of the world. Yes, we want them to be able to be gainfully employed (and become generous alumni donors!), but our goals are bigger, bolder, and more transformative than merely finding a high-paying job after graduation. We want to educate their whole persons to help them live a flourishing quality of life that is healthy and worth living. The good news is that we know how to do this and data from various sources suggest that we are doing it pretty well. The bad news is that this is often a message that is not always so easy for students, parents, and society at large to understand and appreciate in contemporary times when so many think that

20 D.C. Watkins, J.B. Hunt, and D. Eisenberg, "Increased Demand for Mental Health Services on College Campuses: Perspectives from Administrators," Qualitative Social Work, 11(3) (2012), 319-337.

21 A. Colby et al., Rethinking Undergraduate Business Education: Liberal Learning for the Profession (San Francisco: Jossey Bass, 2011).

22 G.M. Manuel, "Spiritual Practices in Psychotherapy: Thirteen Tools for Enhancing Psychological Health" (Half-day workshop presented with T.G. Plante at the 121st annual meeting of the American Psychological Association, Honolulu, HI, 2013); "Santa Clara University Strategic Plan 2011." 
they want to attend "Get Rich U" rather than "Get Transformed U"!

And so in the words of St. Ignatius when he sent Francis Xavier off to Asia for missionary work some 500 years ago, "Go forth and set the world on fire." ${ }^{23}$ This is what we hope our students will do after they walk across that stage in cap and gown on that very special graduation day. Catholic higher education in the liberal arts tradition seeks to help transform students to discover and nurture their gifts and to use them to create a more humane, just, and compassionate world that ultimately helps to build the Kingdom of God.

23 F. Forbes, The Life of St. Ignatius Loyola (Charleston: BiblioLife, 2009). 


\section{Bibliography}

Abrams, T. “The Choice: Colleges Report 20I3 Acceptance Rates.” New York Times, August 8, 20I3, online at http://thechoice.blogs.nytimes.com/2013/04/I5/colleges-report-20I3-acceptance-rates/.

American Academy of Arts and Sciences. The Heart of the Matter: The Humanities and Social Sciences for a Vibrant, Competitive, and Secure Nation (2013). Online at www. humanitiescommission.org/_pdf/hss_report.pdf.

Auletta, K. "Get Rich U.” The New Yorker, April 30, 2012, 38-47.

Colby, A., Ehrlich, T., Sullivan, W.M. \& Dolle, J.R. Rethinking Undergraduate Business Education: Liberal Learning for the Profession. San Francisco, CA: Jossey Bass, 20II.

Dreher, D.E. \& Plante, T.G. "The Calling Protocol: Promoting Greater Health, Joy, and Purpose in Life." In T.G. Plante \& C.E. Thoresen, eds. Spirit, Science, and Health: How the Spiritual Mind Fuels Physical Wellness. Westport, CT: Greenwood Publishing Group, 2007, I29-I42.

Forbes, F. The Life of St. Ignatius Loyola. Charleston, SC: BiblioLife, 2009.

Gallagher, Brenden. "The io Most Worthless College Majors.” Complex, April iг 20 гз Online at http://www.complex.com/city-guide/2013/04/Io-most-worthless-collegemajors/.

Ganss, George E., S.J. Ignatius of Loyola: The Spiritual Exercises and Selected Works. New York, NY: Paulist Press, I99I.

Jonte-Pace, D. \& Brown, P. "Ignatian Values in the Core Curriculum." Conversations on Jesuit higher education 38 (2010), Article I2. Online at http://epublications.marquette. edu/conversations/vol38/issi/I2.

Hart Research Associates. "It Takes More Than a Major: Employer Priorities for College Learning and Student Success." The Association of American Colleges and Universities, April Io, 2013. Online at http://www.aacu.org/leap/documents/2013_EmployerSurvey.pdf.

Heller, N. “Laptop U: Is College Moving Online?” The New Yorker, May 20, 2013. Online at http://www.newyorker.com/reporting/2013/05/20/130520fa_fact_heller.

Higher Education Research Institute. The CIRP Freshman Survey. Online at http://www. heri.ucla.edu/cirpoverview.php.

Hwang, J.Y., Plante, T. \& Lackey, K. "The Development of the Santa Clara Brief Compassion Scale: an Abbreviation of Sprecher and Fehr's Compassionate Love Scale.” Pastoral Psychology, 56(4) (2008), 42I-428.

Jue, K. “Computer Science Becomes Stanford's Most Popular Major." The Stanford Daily, July I9, 20I2. Online at http:/www.stanforddaily.com/2012/07/19/computerscience-becomes-stanfords-most-popular-major/.

Manuel, G.M. Spiritual Practices in Psychotherapy: Thirteen Tools for Enhancing Psychological Health. Half-day workshop presented with T.G. Plante at the I2 Ist annual meeting of the American Psychological Association, Honolulu, HI, 2013.

Mills, B.A., Bersamina, R.B. \& T.G. Plante. “The Impact of College Student Immersion 
Service Learning Trips on Coping With Stress and Vocational Identity." The Journal for Civic Commitment, 9 (2007), I-8.

National Center for Educational Statistics. "Most popular majors - Fast Facts" (2013). Online at http://nces.ed.gov/fastfacts/display.asp?id=37.

Oman, D., Shapiro, S.L., Thoresen, C.E., Plante, T.G. \& Flinders, T. "Meditation Lowers Stress and Supports Forgiveness Among College Students: A Randomized Controlled Trial." Journal of American College Health, 56 (2008), $569-578$.

Plante, T.G., ed. Religion, Spirituality, and Positive Psychology: Understanding the Psychological Fruits of Faith. Santa Barbara, CA: Praeger/ABC-CLIO, 2012.

Contemplative Practices in Action: Spirituality, Meditation, and Health. Santa Barbara, CA: Praeger/ABC-CLIO, 2010.

Plante, T.G. Spiritual Practices in Psychotherapy: Thirteen Tools for Enhancing Psychological Health. Washington, DC: American Psychological Association, 2009.

Plante, T.G. \& E. Callister. "Does Faith that Does Justice Education Improve Compassion?” In T.G. Plante, ed., Maximize compassion, Minimize Cruelty: Psychological, Spiritual, and Religious Influences. Santa Barbara, CA: Praeger/ABC-CLIO, forthcoming.

Plante, T.G., Lackey, K. \& Hwang, J.Y. “The Impact of Immersion Trips on Development of Compassion Among College Students." Journal of Experiential Education, 32(I) (2009), 28-43.

Plante, T.G. \& Sherman, A.S., eds. Faith and Health: Psychological Perspectives. New York: Guilford, 200I.

Plante, T.G. \& Thoresen, C.E., eds. Spirit, Science and Health: How the Spiritual Mind Fuels Physical Wellness. Westport, CT: Praeger/Greenwood, 2007.

Robst, J. "Education and Job Match: The Relatedness of College Major and Work." Economics of Education Review, 26(4) (2007), 397-407.

Santa Clara University. Santa Clara University Strategic Plan 2011. Online at http://www. scu.edu/strategicplan/20II/.

Shapiro, S.L., Oman, D., Thoresen, C.E., Plante, T. G. \& Flinders, T. “Does Mindfulness Mediate Well-Being Effects? A Controlled Empirical Trial.” Journal of Clinical Psychology, 64 (2008), I-22.

Watkins, D. C., Hunt, J. B. \& Eisenberg, D. "Increased Demand for Mental Health Services on College Campuses: Perspectives from Administrators.” Qualitative Social Work, 11 (3)(2012), 319-337. 